\title{
EDUCAÇÃO FÍSICA NO ENSINO MÉDIO: AS PERCEPÇÕES DOS ESTUDANTES SOBRE AS AULAS
}

\author{
Antonio Carlos da Silva \\ Universidade São Judas Tadeu, São Paulo, São Paulo, Brasil \\ Graciele Massoli Rodrigues \\ Universidade São Judas Tadeu, São Paulo, São Paulo, Brasil \\ Elisabete dos Santos Freire \\ Universidade São Judas Tadeu, São Paulo, São Paulo, Brasil
}

\begin{abstract}
Resumo
O presente estudo objetivou analisar as percepções dos estudantes do Ensino Médio sobre as aulas de Educação Física. Responderam a um questionário 72 estudantes do Ensino Médio, sendo que 14 declararam não participar das aulas ou participar às vezes. Problemas de saúde e vergonha foram as principais justificativas utilizadas por eles. As atividades realizadas estimulam a participação de alguns, mas levam ao afastamento de outros. O desejo por atividades diversificadas é comum. O esporte é apreciado por todos, inclusive por aqueles que não participam das aulas. Entretanto, é importante identificar qual o significado atribuído ao termo, que por vezes parece se confundir com exercício e com jogo. Desta forma, a pesquisa permitiu identificar alguns fatores que influenciam as percepções dos alunos sobre as aulas e a forma como delas participam.
\end{abstract}

Palavras-chave: Educação Física e treinamento. Educação. Ensino Médio.

\section{Introdução}

O desinteresse dos estudantes pelas aulas de Educação Física tem sido investigado por diversos pesquisadores, como Betti e Liz (2003), Darido (2004), Paiano (2006), Almeida et al. (2011), Souza e Pagani (2012) e Freitas et al. (2016). De forma geral, os autores verificaram que a Educação Física está entre os componentes curriculares mais apreciados pelos estudantes, mas não entre os mais relevantes. A participação nas aulas tende a diminuir com o passar dos anos, sendo menor durante o Ensino Médio (DARIDO, 2004).

Entre os fatores que parecem desestimular a participação dos estudantes está a repetição de conteúdos. Para Darido (2004), a predominância do esporte e a reprodução das aulas realizadas no Ensino Fundamental são fatores relevantes, que podem fazer com que o estudante não encontre sentido para a Educação Física. Por outro lado, Betti e Liz (2003), Cardoso e Nunez (2014), Darido (2004) e Souza e Pagani (2012) verificaram que grande parte dos estudantes afirma participar das aulas por apreciar a prática esportiva proporcionada. Os resul- 
tados destas e de outras pesquisas têm evidenciado a necessidade de repensar a organização curricular da Educação Física no Ensino Médio.

Porém, além dos conteúdos propostos, outros aspectos podem influenciar a participação dos estudantes nas aulas. Para Brandolin, Koslinski e Soares (2015), sexo, desenvolvimento motor e características demográficas, entre outros fatores, também podem interferir no nível de satisfação dos estudantes com as aulas. O relacionamento entre os estudantes também pode influenciar a participação deles nas aulas. Paiano (2006) realizou pesquisa com estudantes que evitam participar das aulas de Educação Física e verificou que a agressividade e o desrespeito dos colegas foi um fator apontado por eles para justificar sua reduzida participação. Concordando com Brandolin, Koslinski e Soares (2015), acreditamos que ainda é necessário realizar mais estudos sobre os fatores que influenciam a percepção e a participação dos estudantes nas aulas de Educação Física.

Diante do exposto, elaboramos a presente pesquisa com o objetivo de analisar as percepções dos estudantes do Ensino Médio sobre as aulas de Educação Física. O estudo foi guiado por duas questões de pesquisa: (1) Quais as percepções dos alunos do Ensino Médio sobre as aulas de educação física? (2) Quais fatores estão relacionados à participação dos estudantes nas aulas?

\section{Método}

Para responder às perguntas de pesquisa definidas, foi realizada uma pesquisa qualitativa. Participaram da pesquisa 72 estudantes do Ensino Médio de uma escola da rede privada de São Paulo, situada na zona leste da cidade. Os participantes têm idade entre 13 e 17 anos, de ambos os sexos. Foram convidados para o estudo todos os estudantes regularmente matriculados no Ensino Médio. Foi considerada como critério de exclusão a apresentação de atestado médico que dispensasse o aluno da participação de no mínimo 10\% das aulas de Educação Física.

Para obter as informações necessárias, o questionário foi utilizado como instrumento. Assim, os estudantes responderam ao questionário elaborado pelo próprio pesquisador, composto por questões abertas e fechadas. Nesses questionários, eles deveriam descrever como era a participação nas aulas e os motivos que levavam à participação ou não. Além disso, eles avaliaram suas aulas, relataram quais os conteúdos trabalhados e fizeram sugestões para a melhoria da qualidade.

Antes de iniciar a pesquisa, o projeto foi aprovado por Comitê de Ética em Pesquisa. Em seguida, o representante legal da escola, os pais ou responsáveis e os estudantes manifestaram sua concordância com a realização do estudo. Eles foram informados sobre os procedimentos a serem adotados durante a pesquisa, que a participação deles seria voluntária e, portanto, que poderiam desistir da pesquisa a qualquer momento. Além disso, eles também receberam a informação de que não seriam divulgados os nomes dos participantes ou da escola. Desta forma, o questionário não teve identificação pessoal e foi respondido durante as aulas de Educação Física.

Nos questionários, os participantes deveriam descrever como era a participação nas aulas e apresentar os motivos que levavam à participação ou não. Além disso, eles avaliaram suas aulas, relataram quais os conteúdos trabalhados e fizeram sugestões para melhoria da qualidade das aulas. Para a análise das informações obtidas, foi utilizada a técnica de análise de conteúdo (Franco, 2012), desenvolvida em três etapas. A primeira foi a pré-análise, com a leitura das respostas dos questionários. Na segunda etapa, foram identificadas as ideias centrais e as unidades de significado em cada resposta. Nesta etapa, novas leituras foram realizadas, para garantir a coerência na seleção das unidades. A terceira e última etapa de análise 
envolveu a definição de categorias e subcategorias, a partir da organização das unidades de significado identificadas.

\section{Resultados e discussão}

Participaram do estudo 39 meninas e 33 meninos. Desses alunos, 18 estudam no $1^{\circ}$ ano do Ensino Médio, 23 alunos no $2^{\circ}$ ano no Ensino Médio e 31 no $3^{\circ}$ ano no Ensino Médio. Dos 72 alunos pesquisados, 65 declararam participar das aulas e apresentaram diferentes fatores que estimulam esta participação. Assim, 43\% dos alunos relacionam sua participação nas aulas com o prazer, expresso em frases em que eles declaram gostar ou divertir-se ao realizar as atividades propostas. Esses resultados obtidos são semelhantes aos encontrados em outros estudos. Darido (2004), por exemplo, realizou uma pesquisa com 1.172 alunos e constatou que o prazer é um dos principais motivos utilizados pelos alunos para justificar seu interesse pelas aulas. Com o objetivo de conhecer a perspectiva de estudantes do Ensino Fundamental sobre a Educação Física, Betti e Liz (2003) aplicaram questionários a 151 estudantes do sexo feminino e verificaram que aproximadamente $75 \%$ delas declaram gostar ou gostar muito das aulas.

No presente estudo, alguns participantes afirmaram gostar das aulas porque elas possibilitam a vivência de atividades que lhes são agradáveis, como é possível perceber nas afirmações destacadas abaixo:

Porque meu interesse em práticas esportivas é grande (Aluno 3).

Porque alguns exercícios são legais (Aluna 10).

Gosto de praticar esportes (Aluno 25).

Outros estudantes argumentam que as aulas permitem um espaço para que possam relaxar. Esta ideia pode ser percebida, por exemplo, nas afirmações do aluno 23 e da aluna 61:

É divertido. Me livro das aulas chatas (Aluno 23).

Eu participo porque acho uma forma de sair do "ar" da sala (Aluna 61).

Benefícios trazidos pela Educação Física para a saúde das pessoas foram citados por $14 \%$ dos participantes, para quem as aulas melhoram o desempenho físico e a saúde. Resultados semelhantes são apresentados por Almeida et al. (2011).

Entre os 72 participantes, foi possível verificar que 11 alunos e alunas declararam não participar das aulas e 3 afirmaram participar às vezes. Dessa forma, identificamos que aproximadamente $20 \%$ dos estudantes reconhecem não ter uma participação frequente nas aulas, número bem inferior ao apresentado nos estudos de Darido (2004) e Cardoso e Nunez (2014). Darido (2004) verificou que aproximadamente 43\% dos estudantes afirmaram não participar, ou participar às vezes das aulas, enquanto em Cardoso e Nunez (2014) o valor encontrado foi de $45 \%$, aproximadamente.

A maior participação de estudantes, encontrada no presente estudo, pode estar relacionada a diferentes fatores, como as características específicas da escola, dos alunos, da comunidade e das aulas. Analisar essas características pode permitir ampliar nosso conhecimento sobre o olhar do aluno sobre a Educação Física. Concordando com Brandolin, Koslinski e Soares (2015), muitos autores têm se limitado a diagnosticar a avaliação dos estudantes sobre as aulas, mas poucos procuram compreender quais fatores ou condições influenciam essa avaliação.

Confirmando resultados identificados em outros estudos, foi possível perceber que a participação nas aulas é maior entre os meninos. Assim, dos 14 estudantes que declararam não 
participar ou participar pouco das aulas, 12 são meninas. Brandonlin, Koslinski e Soares (2015) verificaram que a satisfação com as aulas é mais frequente entre os meninos $(90,9 \%)$ que entre as meninas $(69,9 \%)$. Ferreira, Graebner e Matias (2014) constataram que 90\% dos meninos afirmam participar das aulas e 70\% declaram gostar sempre ou muitas vezes das aulas. Já entre as meninas, aproximadamente $30 \%$ não participa ou participa às vezes e mais de $50 \%$ afirma não gostar das aulas ou gostar apenas às vezes.

A análise dos questionários permitiu, ainda, identificar os argumentos apresentados para justificar o reduzido envolvimento na disciplina. A vergonha, os problemas de saúde e a forma como a aula é conduzida foram as justificativas utilizadas por meninos e meninas. A vergonha aparece explicitamente como justificativa para não participar frequentemente das aulas nos argumentos de 6 dos 14 alunos e alunas. Há ainda a aluna 73, que afirma participar quando sabe realizar as atividades propostas na aula. Em seu argumento, é possível supor que essa atitude também esteja relacionada à vergonha, uma vez que a participação nas atividades em que a possibilidade de cometer erros é mais frequente lhe traz insegurança.

Moreno, Polato e Machado (2006) explicam que o sentimento de vergonha é algo frequente entre os estudantes. Para os autores, a vergonha pode estar relacionada às expectativas construídas pelos próprios estudantes, por vezes relacionadas à insatisfação com sua aparência ou ao julgamento que ele mesmo construiu quanto ao seu desempenho motor. Por outro lado, muitas vezes a vergonha não é apenas interna ao aluno, mas tem origem na atitude dos colegas (MORENO, POLATO e MACHADO, 2006). Com frequência, os estudantes relatam situações de intimidação ou discriminação nas aulas, que podem causar vergonha (BONFIM et al. 2012).

Outro argumento apresentado por alunos e alunas que não participam ou participam pouco das aulas foi a existência de problemas de saúde que, na interpretação deles e delas, impossibilitam a prática das atividades propostas em aula. Segundo Ferreira, Graebner e Matias (2014), os problemas de saúde são as justificativas frequentes entre os estudantes que não participam das aulas de Educação Física, independentemente do gênero.

A forma como a aula é realizada também aparece nos argumentos de estudantes que não participam, como é possível perceber nos trechos destacados:

Acho que as aulas deviam ensinar mais os fundamentos, e não ser uma aula livre (Aluna 36).

Quando o professor pede eu sempre faço, e gosto bastante quando fazemos algo que eu gosto e quando sei (Aluna 73).

Críticas à forma como as aulas são conduzidas aparecem também na literatura. Já em 1999, Rangel Betti argumentava que os estudantes desejavam aulas diferentes, que permitissem a vivência de outras práticas motoras além do esporte. Souza e Pagani (2012) verificaram que a metodologia das aulas foi apontada por $21 \%$ dos estudantes como um fator que leva à não participação.

\section{A avaliação sobre a Educação Física}

Para compreender como os estudantes avaliam e atribuem significado à Educação Física, solicitamos que eles apontassem os aspectos que consideravam positivos ou negativos de sua experiência com o componente curricular na escola. Ao construir esta avaliação, os estudantes focalizaram seu olhar para três aspectos: sua relação com a aula, a contribuição da aula para a vida fora da escola e a relação com os colegas.

A partir desta análise, ao avaliar os pontos positivos identificados pelos alunos, foram construídas três categorias diferentes: (1) atividades realizadas; (2) consequências ou benefí- 
cios das aulas; e (3) interação com os colegas. A análise detalhada de cada categoria permitiu identificar subcategorias, apresentadas no Quadro 1.

\begin{tabular}{|c|c|c|}
\hline Categorias & Subcategorias & Exemplo de resposta \\
\hline \multirow[t]{3}{*}{ Atividades realizadas } & $\begin{array}{l}\text { Atividades em si: jogos, exercí- } \\
\text { cios, esporte, movimentos }\end{array}$ & $\begin{array}{l}\text { Eu poder me mover (Aluna 40) } \\
\text { Movimentar o corpo (Aluna 55) } \\
\text { Poder fazer os esportes (Aluna 71) }\end{array}$ \\
\hline & Prazer/diversão & $\begin{array}{l}\text { Nos divertimos e aprendemos coisas que não } \\
\text { sabemos (Aluno 56) }\end{array}$ \\
\hline & Diversificação & $\begin{array}{l}\text { Modalidades que possuem muitas variedades e } \\
\text { aprendemos esportes que não sabíamos (Aluno 6) }\end{array}$ \\
\hline \multirow[t]{3}{*}{$\begin{array}{l}\text { Consequências ou } \\
\text { benefícios da aula }\end{array}$} & Condicionamento físico & $\begin{array}{l}\text { O ponto positivo é o condicionamento físico } \\
\text { (Aluno 17) }\end{array}$ \\
\hline & Saúde & $\begin{array}{l}\text { Atividades físicas são boas para a saúde (Aluna } \\
\text { 75) }\end{array}$ \\
\hline & Emagrecimento & Me incentiva a emagrecer (Aluna 22) \\
\hline $\begin{array}{l}\text { Interação com os } \\
\text { colegas }\end{array}$ & & $\begin{array}{l}\text { As duas salas do } 3^{\circ} \text { ano conseguem ficar juntas } \\
\text { (Aluno 20) } \\
\text { Integração entre os colegas de classe (Aluno 39) } \\
\text { Aprender a interagir e trabalhar em grupo (Aluna } \\
\text { 45) }\end{array}$ \\
\hline
\end{tabular}

Quadro 1 - Detalhamento dos pontos positivos identificados

Fonte: Os autores, 2016

Na categoria atividades realizadas, foram reunidas as declarações dos estudantes que consideraram positivas as experiências diversas, proporcionadas pelas aulas. Resultados semelhantes foram identificados nos estudos realizados por Darido (2004), Souza e Pagani (2012) e Freitas et al. (2016). Como explica Darido (2004), experiências positivas podem influenciar a prática de atividades físicas no futuro. Constituem esta categoria três subcategorias. A primeira delas, citada de forma mais frequente, reúne afirmações que expressam valorização da vivência de determinadas atividades, como jogos, exercícios, movimentos e modalidades esportivas.

Doze estudantes citaram como ponto positivo o prazer proporcionado pelas aulas e pelas atividades realizadas, sendo classificadas na subcategoria prazer e diversão. Esta diversão está associada ao que se realiza na aula. A relação entre a participação nas aulas de Educação Física e o prazer é apontada em outros estudos que investigaram a percepção discente sobre o componente curricular, como Darido (2004) e Perfeito et al. (2008).

Já a terceira subcategoria é constituída por afirmações que consideram como pontos positivos a possibilidade de experimentar o novo, a diversidade de práticas motoras. Embora citada por apenas oito alunos e alunas, este é um sinal de que eles e elas tiveram oportunidade de conhecer práticas diversas e que as aulas não apresentaram apenas um limitado número de modalidades esportivas, diferentemente do que acontecia com os estudantes que participaram do estudo mencionado por Rangel-Betti (1999).

A categoria consequências ou benefícios da aula foi construída a partir da identificação de que alguns alunos consideraram como ponto positivo as consequências por eles percebidas com a participação nas aulas. Assim, alguns estudantes afirmam que a participação nas aulas pode melhorar sua condição física, contribuir para a melhoria da saúde ou facilitar a perda de gordura corporal. Com a análise das respostas foi possível identificar três subcategorias: condicionamento físico, saúde e emagrecimento. No estudo realizado por Cardoso e Nunez (2014), saúde e bem-estar foram considerados benefícios das aulas de Educação Física por aproximadamente 59\% dos participantes. No estudo realizado por Betti e Liz (2003), a valorização da saúde é ainda mais frequente, sendo que $92 \%$ das meninas participantes afir- 
maram que entre os benefícios das aulas de Educação Física está sua contribuição para a melhora da condição física e da saúde.

A possibilidade de interação com os colegas constitui a terceira categoria, sendo identificados 13 alunos que consideram positiva a oportunidade que a aula de Educação Física oferece para que eles encontrem os amigos e solucionem problemas em equipe. $\mathrm{O}$ relacionamento entre os alunos é considerado aspecto importante por participantes de outros estudos. Cardoso e Nunez (2014) verificaram que 18,7\% dos estudantes que participaram de sua pesquisa consideram a interação social como o principal objetivo das aulas de Educação Física.

$\mathrm{Na}$ análise dos pontos positivos, percebem-se algumas diferenças entre meninos e meninas em duas categorias. Os meninos são maioria entre aqueles que apontam como ponto positivo as atividades realizadas. Já as meninas são maioria entre aqueles que apontam os benefícios ou consequências como ponto positivo das aulas. No estudo realizado por Betti e Liz (2003), realizado apenas com meninas, é possível verificar que elas também consideram relevantes os benefícios e as consequências das aulas de Educação Física, como a melhoria da condição física da saúde e o fortalecimento dos músculos. Importante mencionar também que alguns estudantes não identificam pontos positivos nas aulas ou veem como positivo ter apenas o espaço para fazer as atividades que desejarem (aula livre).

Ao apontarem pontos negativos das aulas, os estudantes focalizaram a aula em si e seu relacionamento com os colegas. A partir da análise realizada, foram identificadas três categorias de aspectos criticados pelos estudantes: a organização da aula, as atividades realizadas e o relacionamento com os colegas. A análise detalhada de cada categoria permitiu identificar subcategorias, apresentadas no Quadro 2.

\begin{tabular}{|c|c|c|}
\hline Categorias & Subcategorias & Exemplos de resposta \\
\hline \multirow[t]{3}{*}{ Organização da aula } & Constituição dos grupos & Misturar meninos e meninas (Aluna 43) \\
\hline & Tempo e/ou n ${ }^{0}$. de aulas & Pouco tempo de aula (Aluno 47) \\
\hline & Início da aula & A introdução da aula (Aluno 26) \\
\hline \multirow[t]{2}{*}{ Atividades realizadas } & Repetitivas & Muitas vezes são aulas repetitivas (Aluna 50) \\
\hline & Desagradáveis & $\begin{array}{l}\text { Às vezes tem um esporte que não gostamos de } \\
\text { fazer e somos obrigados (Aluna 75) }\end{array}$ \\
\hline \multirow[t]{3}{*}{$\begin{array}{l}\text { Relacionamento com os } \\
\text { colegas }\end{array}$} & Competitividade & $\begin{array}{l}\text { Competitividade levada muito a sério pelos } \\
\text { meus colegas (Aluna 14) }\end{array}$ \\
\hline & Discriminação & $\begin{array}{l}\text { Dificuldade em enxergar que os alunos possuem } \\
\text { diferentes capacidades (Aluna 16) }\end{array}$ \\
\hline & Desinteresse e não participação & $\begin{array}{l}\text { Muitas pessoas não gostam e fazem de qualquer } \\
\text { jeito e acabam comprometendo o resto da equipe } \\
\text { (Aaluna 58) }\end{array}$ \\
\hline
\end{tabular}

Quadro 2 - Detalhamento dos pontos negativos identificados

Fonte: Os autores, 2016

Na categoria organização da aula, identificamos que grande parte dos alunos considera o tempo de aula inadequado. Alguns estudantes questionam a constituição dos grupos e outros criticam a forma como o professor inicia suas aulas.

Na categoria atividades realizadas, um ponto negativo apontado pelos estudantes foi a repetição de temas desenvolvidos em aula. Darido (2004) afirma que a repetição dos conteúdos é problema comum da Educação Física no Ensino Médio, que reproduz temas apresentados também no Ensino Fundamental. Outro ponto negativo das atividades, na percepção dos estudantes, é a presença de atividades consideradas desagradáveis.

Já na categoria relacionamento com os colegas, os estudantes argumentam que alguns colegas são muito competitivos, enquanto outros consideram negativa a atitude de colegas que discriminam os menos habilidosos. Também avaliando a conduta dos colegas, um grupo de estudantes considera um problema o desinteresse e a não participação dos colegas. Assim, 
é possível perceber que a interação com os colegas, entendida como aspecto positivo por alguns estudantes, é considerada um ponto negativo por outros. Esta visão negativa, relacionada ao excesso de valorização da competição e à discriminação, pode também estar relacionada com a vergonha, causa apontada por alguns estudantes para justificar sua não participação nas aulas, como apresentado anteriormente.

A atitude dos colegas é um fator que pode afastar os estudantes das aulas, como explica Paiano (2006). Ao realizar entrevistas com 17 estudantes que apresentavam excesso de falta nas aulas de Educação Física, o autor verificou que a agressividade e o desrespeito dos colegas são fatores que têm afastado esses estudantes das aulas.

\section{Sobre os conteúdos da Educação Física}

Quando questionados sobre os conteúdos apresentados nas aulas, os estudantes citam, predominantemente, as atividades realizadas. É possível notar que o esporte aparece entre os conteúdos mais citados. Alguns estudantes mencionam em suas respostas modalidades específicas, como nos trechos destacados a seguir:

Voleibol, futebol, basquete (Aluno 17).

Jogos de futebol, voleibol, handebol e testes (Aluno 29).

Voleibol e handebol (Aluna 50).

Outros, no entanto, mencionam o esporte de forma genérica:

Esportes e suas diferentes modalidades, além das regras e do modo de praticá-las (Aluno 6).

Esportes famosos e alguns que saem do cotidiano, mas é difícil (Aluno 26).

Esportes variados (aluno 49).

Todos os tipos de esportes são comentados, porém, só alguns praticados (Aluna 70).

Embora a palavra "esporte" seja a mais mencionada pelos estudantes, é possível que eles e elas não consigam diferenciar o esporte de outras manifestações da cultura corporal. Não raro, podemos perceber que as pessoas utilizam o termo "esporte" como sinônimo de jogos, atividade física e/ou exercício físico (KNIJNICK e KNIJNICK, 2004). Acreditamos que pesquisas futuras podem explorar em profundidade a relação entre os conteúdos propostos em aula e aqueles percebidos pelos estudantes.

A aprendizagem de jogos também é citada com frequência pelos participantes, assim como a corrida. A aprendizagem sobre a importância do exercício e sobre a saúde também é relatada por parte dos estudantes, como podemos verificar nos trechos apresentados a seguir:

Que é importante fazer atividades físicas (Aluna 45).

Atividades que melhoram o desempenho e saúde corporal (Aluno 47).

A importância das aulas de Educação Física para a saúde também foi conteúdo citado por $27,2 \%$ dos estudantes do Ensino Médio que participaram da pesquisa realizada por Darido (2004).

Quando questionados sobre quais conteúdos deveriam ser ensinados nas aulas de Educação Física, 27 estudantes solicitam a possibilidade de praticar modalidades esportivas, como é possível perceber nos trechos das respostas destacados a seguir:

Esportes em geral (Aluno 4).

Futebol feminino pois não sei jogar (Aluna 62). 
Fundamentos dos esportes, assim aprendemos jogar (Aluna 64).

Esse interesse dos estudantes pelo esporte também foi identificado nos estudos de Betti e Liz (2003), Cardoso e Nunez (2014), Darido (2004) e Souza e Pagani (2012). A solicitação por prática do esporte pode ser reflexo da predominância desse tema nas aulas de Educação Física, predomínio esse já apontado por diversos autores, como Rangel-Betti (1999).

Mas, além do esporte, os estudantes sugerem diversas outras atividades, como natação, ginástica, lutas, dança e jogos diversos. Mas, independentemente da atividade proposta, meninos e meninas expressam seu desejo por atividades diversificadas, como é possível perceber nos trechos das respostas apresentadas abaixo:

Deveria ser abordado esportes mais diferentes, para aulas mais interativas (Aluno 13).

Dança, aquecimento, esportes diferentes de futebol com suas respectivas regras (Aluno 19).

Mais parte de fundamentos, e mais a prática; incentivar mais o pessoal com atividades diferentes a cada aula, onde cada um iria no seu próprio tempo (Aluna 58).

Além disso, chama atenção a sugestão por apresentar conhecimentos sobre o corpo e sobre o movimento, assim como a solicitação para que sejam ensinados atitudes e valores, como aparece nas respostas dos alunos.

Aprender sobre os músculos seria bem interessante (Aluno 28).

Além do jeito certo da prática dos esportes também deveria ensinar os benefícios e malefícios das atividades. Porque com maiores informações fica mais fácil e prazeroso e interessante fazer a atividade (Aluno 47).

Além de esportes, acho que devia ser ensinado a respeitar as diferenças e limitações dos outros (Aluno 39).

\section{O que desejam os estudantes que não participam das aulas}

Ao sugerirem mudanças nas aulas foi possível perceber que os estudantes que declaram não participar desejam atender seus desejos pessoais. Para eles, as aulas de Educação Física são consideradas apenas como espaço para a prática de atividades motoras. Assim, alguns deles solicitam a possibilidade de praticar atividades específicas, como voleibol, dança ou natação. Já outros alunos desejam que os temas sejam abordados de forma diferente, com o ensino das habilidades específicas de cada modalidade.

Outra parcela de estudantes propôs que se ensine nas aulas a importância de respeitar os colegas. Assim, mais uma vez, esses estudantes indicam que a não participação pode estar relacionada ao relacionamento com os colegas, resultado semelhante ao apresentado por Paiano (2006). Esses resultados evidenciam a necessidade de olhar para a construção de um ambiente onde a interação durante as aulas seja marcada pelo respeito às diferenças.

Cinco dos 14 estudantes que não participam das aulas solicitam que sejam realizadas atividades diversificadas, como jogos, brincadeiras ou modalidades esportivas diferentes. Embora a tematização de atividades diversas tenha sido mencionada por alguns estudantes, parece que ela ainda não é suficiente.

A importância de oferecer aos alunos o conhecimento e a vivência de práticas motoras diversas é apontada por inúmeros autores, como Darido (2004), Rangel-Betti (1999) e Cardoso e Nunez (2014), entre outros. Rangel-Betti (1999) afirma que, em pesquisa realizada em 1992, verificara que os estudantes desejavam aprender sobre outros temas. Cardoso e Nunez 
(2014), Ferreira, Graebner e Matias (2014), Freitas et al. (2016) e Darido (2004) também verificaram que os estudantes do Ensino Médio desejam diversificação.

Para Ferreira, Graebner e Matias (2014), uma possível justificativa para a repetição dos temas tratados em aula é a dificuldade de parte de professores e professoras para tratar outros temas da cultura corporal durante as aulas. Muitos deles também não tiveram contato com práticas motoras diversas e podem não se sentir preparados para apresentá-las como tema das aulas. Contudo, diferentes estratégias de ensino podem ser utilizadas por professores e professoras, inclusive envolvendo os próprios estudantes na busca por informações e recursos para a aprendizagem.

Envolver os alunos na construção do currículo é uma forma de possibilitar a diversificação. Brandolin, Koslinski e Soares (2015) verificaram que os estudantes que participam da tomada de decisão nas aulas sentem-se mais satisfeitos com as aulas. Nessa perspectiva, Souza e Freire (2008) defendem a realização do planejamento participativo que, especialmente no Ensino Médio, pode estimular o estudante a tomar decisões sobre os temas a serem discutidos nas aulas, tornando a aprendizagem mais significativa.

Mas é importante questionar se o desejo por diversidade nas aulas não se baseia na concepção de uma Educação Física que tem por objetivo apenas o estímulo ao prazer. O sentido da experimentação nas aulas deve ser discutido com os estudantes, para que as aulas possam influenciar as escolhas dos estudantes sobre suas práticas motoras realizadas no cotidiano.

\section{Considerações finais}

O objetivo desta pesquisa foi analisar a percepção dos alunos do Ensino Médio sobre as aulas de Educação Física. A partir da aplicação de questionários aos estudantes, foi possível confirmar alguns resultados já apresentados na literatura, como o predomínio de meninas entre os estudantes que não participam das aulas ou participam pouco. Além disso, a existência de problemas de saúde é o principal argumento para justificar a não participação nas aulas.

No entanto, a resposta dos estudantes permitiu identificar alguns aspectos pouco analisados na literatura, como a vergonha e o constrangimento relatados por alguns dos estudantes que deixam de participar das aulas. Esses estudantes lamentam a agressividade ou os comentários utilizados por seus colegas, que tentam ridicularizar os estudantes menos habilidosos, e apontam o relacionamento entre os estudantes como um ponto negativo das aulas. Ao mesmo tempo, permitir a interação social entre os estudantes é um ponto positivo das aulas, na concepção dos participantes. Este resultado permite compreender que a relação entre os estudantes é um aspecto importante da aula, que pode influenciar a percepção sobre a Educação Física. Entender se e como esta influência acontece pode ser tema de novos estudos.

Considerando os conteúdos das aulas, foi possível perceber que predomina nos relatos dos estudantes a aprendizagem de conteúdos relacionados ao esporte. Esta predominância parece ser percebida de diferentes formas pelos estudantes. Enquanto um grupo considera como ponto positivo das aulas as atividades realizadas, outro considera que estas atividades, por serem repetitivas ou desagradáveis, são ponto negativo das aulas. A definição dos conteúdos deve manter coerência com os objetivos definidos. Por vezes, os estudantes não conseguem identificar quais são os conteúdos das aulas e entendem a Educação Física como espaço para o lazer ou para o exercício físico. Uma forma de levá-los a refletir sobre os conteúdos a serem aprendidos e, por consequência, sobre os objetivos do componente curricular é a elaboração do planejamento com o envolvimento dos estudantes. 


\title{
PHYSICAL EDUCATION IN HIGH SCHOOL: THE PERCEPTIONS OF STUDENTS ABOUT THE CLASS
}

\begin{abstract}
This study aimed to analyze the perceptions of high school students about the physical education classes. 72 students answered a questionnaire and 14 said they did not attend classes or participate sometimes. Health problems and shame were the main arguments used by them. The activities encourage the participation of some, but lead to the removal of others. The desire for diversified activities is common. The sport is enjoyed by everyone, including those who do not participate in the classes. However, it is important to identify the meaning given to the term, which sometimes seems to be confused with exercise and play. Thus, the research allowed to identify some factors that influence the students' perceptions about the classes and how they participate.
\end{abstract}

Keywords: Physical Education and Training. Education. High School.

\section{EDUCACIÓN FÍSICA EN LA SECUNDARIA: LAS PERCEPCIONES DE LOS ES- TUDIANTES SOBRE LAS CLASES}

\begin{abstract}
Resumen
El objetivo de este estudio fue analizar las percepciones de estudiantes de la enseñanza secundaria sobre las clases de Educación Física. Para eso, 72 estudiantes de la escuela secundaria respondieron un cuestionario y, 14 de ellos dijeron que no participan de las clases o participan poco. Problemas de salud y vergüenza fueron las principales justificativas utilizadas por ellos. Las actividades incentivan la participación de algunos estudiantes, pero, al mismo tiempo, originan el alejamiento de otros. El deseo de realizar actividades diversificadas es común. El deporte es apreciado por todos, incluso por aquellos que no participan de las clases. Sin embargo, es importante identificar el significado dado a ese término, que a veces parece ser confundido con el ejercicio y con el juego. Por lo tanto, la investigación permitió identificar algunos factores que influyen en las percepciones de los estudiantes acerca de las clases y de su participación en ellas.
\end{abstract}

Palabras-clave: Educación y Entrenamiento Físico. Educación. Secundaria.

\section{Referências}

ALMEIDA, A. B.; TUCHER, G.; ROCHA, C. A. Q.; PAIXÃO, J. A. Percepção discente sobre a Educação Física escolar e motivos que levam à sua prática. Revista Mackenzie de Educação Física, v. 10, n. 2, p. 109-116, 2011.

BETTI, M.; LIZ, M. T. F. Educação física escolar: a perspectiva de alunas do ensino fundamental. Motriz, v. 9, n. 3, p. 135-142, 2003.

BOMFIM, D.; CAMPBELL, C. S. G.; MORAES, J. F. V. N.; FRANCO, A. M.; CUNHA, V. N. C.; FRANÇA, N. M.; FERREIRA, S. M. B. Ocorrência de bullying nas aulas de educação física em uma escola do Distrito Federal. Pensar a Prática, Goiânia, v. 15, n. 2, p. 302-317, 2012. Disponível em: <http://www.revistas.ufg.br/index.php/fef/article/view/12520/11202>. Acesso em: 20 ago. 2014. 
BRANDOLIN, F; KOSLINSKI, M.C; SOARES, A. J. A percepção dos alunos sobre a educação física no ensino médio. Revista de Educação Física, v. 26, n.4, p.601-610, 2015. Disponível em: <http://periodicos.uem.br/ojs/index.php/RevEducFis/article/view/29836>. Acesso em: 14 maio 2016.

CARDOSO, A.G., NUNEZ, P.R.M. Percepção dos alunos do ensino médio em relação às aulas de educação física. Coleção Pesquisa em Educação Física, Várzea Paulista, v. 13, n. 4, p. 125-132, 2014.

DARIDO, S. C. A educação física na escola e o processo de formação dos não praticantes de atividade física. Revista Brasileira de Educação Física e Esporte, v. 18, n. 1, p. 61-80, 2004.

FERREIRA, L. S. F.; GRAEBNER, L.; MATIAS, T. S. Percepção de alunos sobre as aulas de Educação Física do Ensino Médio. Pensar a prática, v. 17, n. 3, p.734-750, 2014.

FRANCO, M. L. P. B. Análise de conteúdo. 4. ed. Brasilia: Liber Livros, 2012. v. 1. 94p.

FREITAS, J. F.; SILVA, J. E. B.; LACERDA, M. R. A.; LEONARDI., T. J. A identidade da Educação Física Escolar sob o olhar dos alunos do $5^{\circ}$ ano do ensino fundamental I. Pensar a Prática, v. 19, n. 2, p. 396-409, abr./jun. 2016.

KNIJNIK, J. D.; KNIJNIK, S. C. F. Sob o signo de ludens: interfaces entre brincadeira, jogo e os significados do esporte de competição. Revista Brasileira de Ciência e Movimento, v. 12, n. 2, p. 103-109, 2004.

MORENO, B. S.; POLATO, A. L.; MACHADO, A. A. O aluno e seu corpo nas aulas de educação física: apontamentos para uma reflexão sobre a vergonha e a mídia. Movimento \& Percepção, Espírito Santo de Pinhal, v.6, n.8, p. 85-104, jan./jun. 2006.

PAIANO, R. Possibilidades de orientação da prática pedagógica do professor de Educação Física: situações de desprazer na opinião dos alunos. Revista Mackenzie de Educação Física e Esporte, v. 5, n. 1, 2006.

PERFEITO, R. B.; GUIMARÃES, A. C. A.; MARIA, W. B.; SOARES, A.; SANTOS, M. B. Avaliação das aulas de educação física na percepção dos alunos de escolas públicas e particulares. Revista de Educação Física/UEM, Maringá, v. 19, n. 4, p. 489-499, 2008.

RANGEL- BETTI, I. C. Esporte na escola: Mas é só isso professor? Motriz, v. 1, n. 1, p. 25$31,1999$.

SOUZA, A. G., FREIRE, E. S. Planejamento participativo e Educação Física: envolvimento e opinião dos alunos do ensino médio. Revista Mackenzie de Educação Física e Esporte, São Paulo, v. 7, n. 3, p. 29-36, 2008.

SOUZA, F. T. R.; PAGANI, M. M. A Educação Física escolar do Ensino Médio: a ótica do aluno. Revista Educação, Cultura e Sociedade, v.2, n.2, p.109-119, jul./dez. 2012. 
Recebido em: 24/10/2016

Revisado em: 14/04/2017

Aprovado em: 28/08/2017

Endereço para correspondência:

elisabetefreire@uol.com.br

Elisabete dos Santos Freire

Universidade São Judas Tadeu,

Curso de Educação Física.

Rua Taquari, 541

Mooca

03183000 - São Paulo, SP - Brasil 